\title{
An Operations Improvement Plan for Engineering Company
}

\section{Jia HONG}

Chengdu Spaceon Group Co., Ltd.

\begin{abstract}
Some engineering companies which design and produce engineering equipment and systems have deficiency of unstable product quality followed by gradually raised costs for after-sales maintenance and repair. The purpose of this report is to help explore and discuss possible issues which may contribute to this deficiency and then to seek solutions for better operations management. Methodologies such as performance control system, material management, quality management and inter-relationships management were learned from, while adopted techniques and tools contain: EOQ, TQM, ISO approach, Six Sigma, ServQual, value-chain approach and PDCA. Based on step-by-step analysis, the report recommends introduction of performance control, material management techniques, R\&D databases and further standardization, quality management, and inter-relationships methodology.
\end{abstract}

Keywords: engineering company; operations management; performance control; material management; R\&D database; quality management; departmental cooperation

DOI: $10.36012 / \mathrm{ems} . v 1 \mathrm{i} 2.1833$

\section{Introduction}

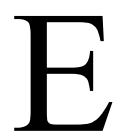

ngineering companies design and produce engineering equipment and systems. Some of them have relatively mature operations model, capable of providing total solutions and turn-key systems to the clients, with customers helping contribute good revenue and profits, yet their unstable product quality followed by gradually raised costs for after-sales maintenance and repair becomes a big deficiency for such companies.

The purpose of this report is to help explore and discuss some possible issues which may contribute more or less to this deficiency and then to seek solutions for better operations management. One limitation should be noted that: business numbers cannot be accessed, so quantitative analysis is not provided.

Methodologies such as performance control system, material management, quality management and inter-relationships management were learned from, while adopted techniques and tools contain: EOQ, TQM, ISO approach, Six Sigma, ServQual, value-chain approach and PDCA.

The report consists of two main sections: problem analysis and reflections on the key questions, which contain both problem statement and a range of possible ways for solution; and a set of practical recommendations with their justification and sensible actions.

\section{Problem Analysis and Reflections on the Key Questions}

\subsection{Problem Analysis}

Since the companies are designer and manufacturer of equipment and systems in the field of engineering, there exist various issues in different phases, leading to the gradually raised costs for after-sales maintenance and repair as the current deficiency, which are addressed below separately. 


\subsubsection{Issue One - Quality Problems with Purchase and Outsourcing}

At the very beginning of internal supply chain, the collection of materials could be done through both component purchase and equipment or subsystem outsourcing from a large number of different suppliers and subcontractors.

For some big companies, a separated purchase department implements centralized purchase function ${ }^{[1]}$. It has many advantages such as: 'better price', preferential satisfaction by the supplier, well trained and focused purchase group who can better monitor and provide specialized suggestion to supplier, standardization of purchase procedure, and saved transport.

However, many kinds of quality issues are likely to happen due to defective purchase standard, unfixed outsourcing channel, corruption and theft, and lack of monitoring and evaluation. This could become much worse when the client needs total solution and turn-key product.

2.1.2 Issue Two - Wasted Repetition at the R\&D Stage

Engineering companies can adopt pull system and/or push system as operations manner, and gain profits by both universal goods and customized contract accordingly.

When it manufactures or launches mass production of the universal goods, namely off-the-shelf product, no extra money or time is put into $\mathrm{R} \& \mathrm{D}$, but the manufacture department becomes the kernel section in this case.

However, when it comes to customer-tailored contracts for total solution and turn-key system, each new contract takes relatively a long time, usually from months to a year, for proposal making, R\&D including design reviews at certain phases, which mostly happen in R\&D department.

Take electronics engineering system for example, from the prospective of hardware, it is integrated from several subsystems, each of which is again composed of some complete built units, which are built up from processing units and peripheral circuits etcetera. It is a complicated project, along with the software functions realization including delicate programming and debugging in every hardware section. For successful and speedy delivery, it is necessary for an engineering company to accumulate technological strength and apply the same or similar technology to customized but internally connected projects.

Many companies, in this regard, try to adopt the same R\&D teams, same or similar technology and design steps for customized but internally connected projects, however, most of them cannot be called mature and even not standardized. For example, neither a new coming hardware technician or engineer could get a modularized or standardized hardware plan to follow with, nor even an experienced engineer has a mature software database to pick up the basic program from. It causes severely redundant repetition at the $R \& D$ stage, resulting in not only a big waste of manpower and time, but also insecure product quality.

\subsubsection{Issue Three - Quality Control Defects}

According to Wright ${ }^{[1]}$, quality consideration is always very vital for an organization to compete in the nation and further in the global market, which influences the customer satisfaction directly, and also plays back on the utilization efficiency of resources.

Engineering companies cannot always be defined as good practitioners on quality control, with possible defects described below.

(1)Although complying with either national or international quality standards during design and manufacture, companies seldom invite a third party as a quality supervisor, but rely on their own quality department for quality control.

(2) When quality issue or incident emerges, besides the correction, formal actions are taken to dig out the true reason and to avoid reoccurring, but this is far from enough and they need standards to conform with and statistical approach to solve the problem of unstable product quality.

2.1.4 Issue Four - Departmental Cooperation Problems A complete engineering company may run various functional departments, including R\&D department, departments of new technology, manufacture, batch production, marketing \& sales, projects surveillance, QC and purchase, as well as IT help centre and other managerial departments like HR, covering each step of value adding processes, along with support of non-value adding processes. Such companies have its own work teams for product design, manufacture and marketing. It sometimes produces a big saving on product 
lead time and the costs, compared with smaller companies, which may need more product lead time and costs for development and delivery, as they only conduct manufacture or design, and so their contracting with distributors or agencies are needed. Yet, at least three usual deficiencies lie in a complete engineering company's traditional operations management regarding departmental cooperation, which could lead to unstable product quality.

(1) Isolation between any two departments, resulting in staff aware of neither another department's objectives within a certain project, nor the final goal and target of the whole project. They usually only care about their intermediate product as the departmental outcome and the specific interests of their department, which actually causes failure of departmental communications.

(2) Although the overall project planning is well organized by some managerial department, less effective and inefficient implementing and controlling of project due to both weakness of the project manager, and lack of relevant mechanism and technology such as IT strategy for the project being processed and controlled smoothly as a whole.

(3) Unhappy workers due to unbalanced profits and thus thinner monthly rewards compared with staff in other departments, also contribute to the unstable product quality. The new technology department, for example, which does not meet the external client directly, but takes R\&D department as its internal client instead, does 'not show up on the value chain' ${ }^{[1]}$, thus it generated some unhappy workers in response.

\subsubsection{Overall Problem Statement}

Targeting the unstable product quality and thus gradually raised costs for after-sales maintenance and repair, an overall problem statement thus can be drawn from the above analyses.

(1) At the stage of collecting resources, some quality issues are likely to happen due to defective purchase standard, unfixed outsourcing channel, and lack of monitoring and evaluation.

(2)Databases in R\&D department are yet to be established. This causes severely redundant repetition at the R\&D stage, resulting in not only a big waste of manpower and time, but also unstable product quality.

(3) I n regards to quality control, engineering companies need standards to conform with and statistical approach to solve the problem of unstable product quality. Besides, they need more participation of third-party supervisory unit.

(4)For the departmental cooperation, lack of mutual understanding and communications, weak top-level project management with new technological strategy and unhappy worker caused from developmental unbalance between departments also contribute to the focused deficiency.

\subsection{Possible Ways of Solution}

2.2.1 Reflections on Quality Problem with Purchase and Outsourcing

With different natures of products, engineering companies take different supply chain strategies, for example, the pull system which generally corresponds to the batch production of universal goods without customer's anticipation; and the push system which is always for the customized contract and will not start value adding process until customer input. Accordingly, there are two operations structures shown as below ${ }^{[1]}$.

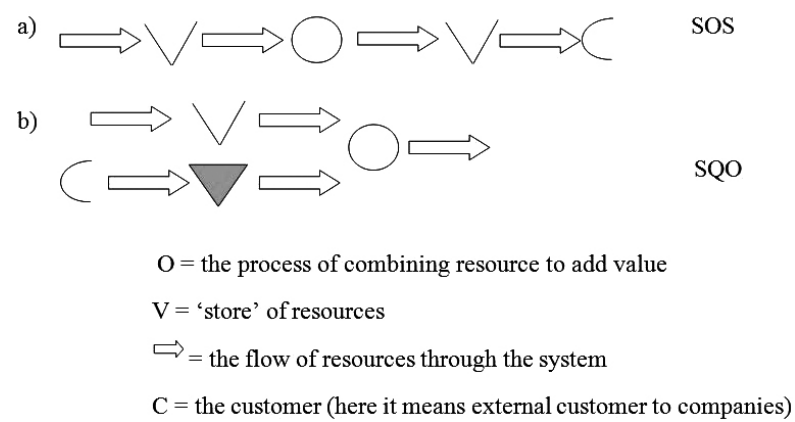

Figure 1. Two Operations Structures

As can be seen from the figure above, the 'store' of resources comes at an early stage no matter which structure the operations take, so it needs to be strictly monitored and controlled. Meanwhile, compared to structure a), structure b) with the input of client's 'push' needs more emphasized concerns for both component purchase and subsystem outsourcing, especially for the coloured ' $\mathrm{V}$ ' due to its strictly scheduling demand or otherwise compromised quality of resources.

For the purchase and outsourcing problems mentioned at 2.1.1, suggestions are economic order quantity (EOQ), 'supply chain approach' which requires 'close relationship with suppliers ${ }^{\text {'[1] }}$, accuracy of ' stock records' ${ }^{[1]}$ through various actions and IT strategy like 
'barcode' and RFID, and a new systematic method for supplier selection, procedure monitoring and assessment after purchase and outsourcing.

2.2.2 Reflections on Wasted Repetition at the R\&D Stage

Several strategies for developing a new product were mentioned by Wright ${ }^{[1]}$, among which the first two strategies could be observed in engineering companies:

Some organizations will position themselves as market leaders; this can be a high-risk strategy as time and money will be required to develop and set up the infrastructure needed. On the other hand, being first in the market can reap large benefits.

Others will seek to imitate the innovations of other organizations and will attempt to join the initial growth phase of a new product.

When an engineering company tries to be an industrial leader in its own area, it is not strange for it to simultaneously take the above two strategies. For those strategies, Wright ${ }^{[1]}$ also suggested necessary conditions including 'lead time, from concept to market, has to be minimized'. So, the relatively long time from months to a year, for a new product or system's proposal making, $R \& D$ and design reviews at certain phases, must be minimized in the $R \& D$ department of engineering companies.

One of the solutions is to establish various databases to avoid severely redundant $R \& D$ repetition, and to further and gradually achieve R\&D standardization as the second step.

\subsubsection{Reflections on Quality Control Defects}

Quality management improvement involves sufficient investment and manpower input and yet cannot make obvious profit immediately. Furthermore, the best quality doesn't mean the highest profit, which can be seen from the following figure.

Obviously in the figure 2, the point of 'quality level for minimum quality cost' probably cannot reach customer's satisfaction, let alone exceed it. So, the quality control defects are likely due to the following reasons:

(1) Budget limit or just keep the investment at the lowest level of COQ

(2) There are more important focuses like fast delivery, quantity and high technology etcetera

(3)Currently sound relationship with existing

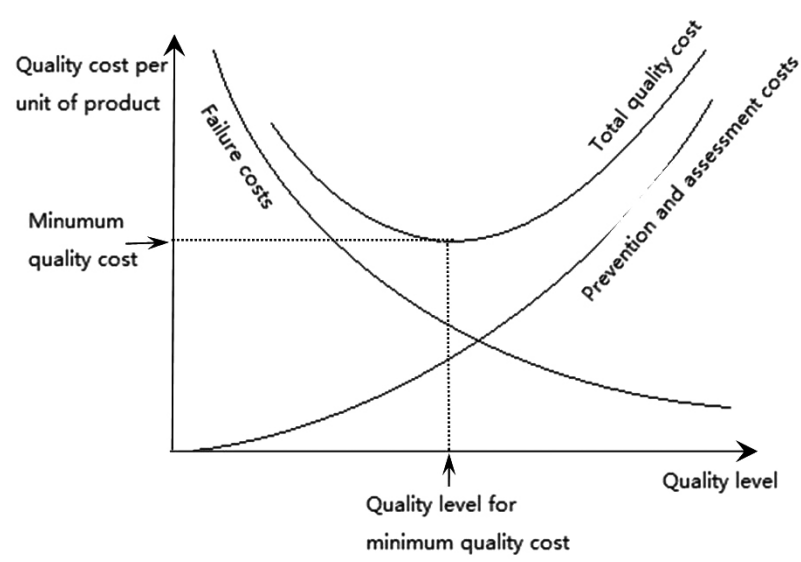

Figure 2. Cost of Quality (COQ)

customers

It seems acceptable to some engineering companies with still relatively stable annual profits, and it saves money by using their own quality control department, however speaking in a long term, the possible accumulation of quality risks, contract violations, administration costs due to after-sales maintenance and repairs, and the loss of customer and even reputation cannot be neglected. On the contrary, Wright ${ }^{[1]}$ said the 'higher quality' will eventually result in cost reduction, profit rising, 'growth and survival'.

From analysis above, it is an immediate necessity for engineering companies to strengthen their quality control management, through a wide exploration of TQM, ISO approach, Six Sigma and ServQual.

2.2.4 Reflections on Departmental Cooperation Problems

While enjoying the advantages brought from a whole set of departments providing functions from purchase to delivery, which saves time and resources, three mentioned issues relating to departmental cooperation may all be caused from: compared with the business supply chain including suppliers and customers, the company management perhaps doesn't pay enough attention to the inner operations, which should also be treated technically as the internal supply chain. Actually, similar with supply chain approach, many actions relating to inter-relationships can be taken for improving departmental problems.

As Wright ${ }^{[1]}$ mentioned, modern supply chain takes all steps and elements within it as a whole, aiming at the same objective. Also it is an open system by sharing information among all participants, and is opti- 
mized by technical strategies like IT approach. The best supply chain takes care of benefits of all members other than focusing on manufacturer's profit by sacrificing that of supplier or distributor. All these features and methods can also apply well to the internal supply chain.

\section{Recommendations}

The four issues discussed above seem independent with each other, but actually as they lead to the same deficiency of the unstable quality, some may have common reasons and mechanisms, such as lack of standardization, so that they can and are better to be treated or remedied as a whole for efficiency and consistency. The modern operations management involves development and optimization which covers the whole value adding process from material to the customer and also engages the necessary non-value adding activities within the company. As a result, a range of responses drawn from operations management system, concerning engineering company's actual issues, are suggested as following, each supported by justification and implementation steps.

\subsection{Introduce Performance Control}

Some engineering firms lack of performance control and standard of performance. The project manager conventionally relies on old experience, sets up every step for purchase, R\&D, production, quality control and delivery, which looks like very systematic and convincing. However it will cost much more for any remedy or correction, either before or after product delivery.

On the contrary, the most essential point of the modern performance control system emphasizes setting up the standard before any substantial action, since the earlier the setting up of standard, the better performance can be achieved with less budget. Likewise, 'the more detailed the plan, the more control can be achieved' ${ }^{[1]}$.

Actually, performance control system needs to be adopted, due to the following reasons:

(1) The purchase and outsourcing including supplier selection, channel monitoring, and corruption and theft prevention has to meet some standard for procedure improvement.

(2) The R\&D database itself is a standard and also needs feedback, measurement and adjustment.
(3) Performance control system is especially useful against the quality control defects, since the performance of the product quality impact directly on satisfaction level of the customer.

The best performance control lies in four steps ${ }^{[1]}$ : formulate standards, collect performance feedback, measure and evaluate, and adjust actions, to implement which in engineering firms, there would be at least these considerations ${ }^{[1]}$ :

(1)Compared with service provider, 'hard measurement criteria' are more important to a manufacturing company and easier to formulate, so the first step can involve making criteria of purchase cost, outsourcing delivery time, R\&D lead time, production quantity and number of customer complains etcetera, while soft criteria are also required like friendly human machine interface, easy to learn by customer, aesthetic outline, and enthusiastic and helpful on-site staff and trainers.

(2) since the feedback has to be accurate, identifiable and timely, companies need to set up regular feedback collection mechanism, with responsibility assigned to certain staff, for the voice both from customer or end user, and from the department as another department's internal client.

(3) The comparison between actual performance and the expected one has to follow right instructions, otherwise staff can pick out lots of extra information and concentrate, which is wasting, especially in bigger companies with many employees and departments.

(4)Put the adjustment and correction at a low level to the greatest extent, which saves time and decreases misunderstanding during information transfer. Meanwhile, the decision-making staff has to be 'well trained' and empowered to appropriate extent. The correlation between departments should also be considered so as not to take action while sacrificing performance of another department.

\subsection{Adopt Material Management Techniques on Purchase and Outsourcing}

As a main section of material management, purchase and outsourcing management can be considerably improved by various mature techniques.

(1) The economic order quantity (EOQ) is used to calculate and suggest the best order amount, so as to avoid surplus order induced by corruption, and conse quently out-of-date quality problem, or when R\&D de- 
mand and new technological reserve requirement may lead to extra purchase and outsourcing.

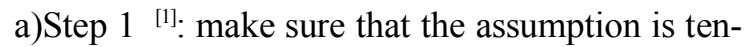
able, containing constant and visible demand, timely and right delivery, and no damage or theft happening.

b)Step 2 [1]: use ' $\mathrm{Q}=\sqrt{\frac{2 \mathrm{DO}}{\mathrm{PH}}}$, where: $\mathrm{Q}=$ reorder quantity; $\mathrm{D}=$ Annual demand; $\mathrm{O}=$ Cost of each order; $\mathrm{P}=$ Price per unit; $\mathrm{H}=$ Inventory holding cost.

(2) While engineering firms sometimes keep a large number of stock on hand, the accuracy of "stock records' counts a $\operatorname{lot}^{[1]}$. Various actions and regulations can be utilized, as well as IT strategies like EPC and RFID.

(3) Establishment of "close relationship with suppliers' ${ }^{\left[{ }^{1]}\right.}$ suits for loyal suppliers with quality and time assurance, meanwhile, a systematic and strict procedure for new supplier selection, and purchase monitoring and assessment after purchase and outsourcing should be created, not only by the purchase department, but also all other relative sections including $\mathrm{R} \& \mathrm{D}$ and mass production.

(4)Select as many domestic resources as possible to reduce logistics cost and suppliers management $\cos ^{t^{2]}}$.

\subsection{Establish R\&D Databases and Further Stan- dardization}

As analyzed before, the redundant $R \& D$ repetition can be eliminated by establishment of R\&D databases, and further technical standardization would help improve company competitiveness.

For establishing and using databases:

(1) Determine and set up database entrance standards for different working groups separately.

(2) Manage databases by specific staff and get them updated under principle of PDCA.

(3) When designing a new product, conduct demand determination, 'systematic and rapid screening of various alternatives', select design and program prototypes from databases, and then add no change or less change to the exiting prototypes for development ${ }^{[1]}$.

The technical standardization is also a necessary step for engineering firms, which helps obtain interoperability and compatibility with global market, so as to achieve industrial recognition and 'networking opportunities' with international experts. Moreover, it helps gain the improve ment of product quality, high-level testability complying with international testing standard, and higher competitiveness ${ }^{[3]}$.

Standardization library, a popular name of the above concept, was also studied by Yi and Tang[4], who proposed a management committee for the library's planning, construction, operation, maintenance and effects, an office for its dynamic management and rule making regarding reward-and-punishment etcetera, a technical expert group for selection criteria, and a product expert group responsible for application preview and evaluation of the selected module.

\subsection{Strengthen Quality Management}

The suggestion for quality management begins from exploration of the four levels: 'inspection, control, assurance' and total quality management (TQM)[1]. It's not hard for engineering companies to reach the second level - quality control, which means they can inspect and correct errors, then find out the causes, and finally take measures to 'prevent errors reoccurring, ${ }^{[1]}$.

With the target of the quality assurance, companies need to set up standards and norms to conform with rigidly. Furthermore, the final goal, TQM requires a 'TQM culture' ${ }^{[1]}$ from the top management to the bottom, and cannot be achieved in a short time.

Although most American and European firms prefer quick results other than Japanese manner ${ }^{[1]}$, it is recommended that engineering companies aim at TQM for its long-term technological and service development.

To eventually launch the goal of TQM, the following five steps are recommended:

(1) Use ServQual approach to investigate customer's expectation and the 'five gaps' ${ }^{[1]}$.

(2)By complying with ISO series, set up quality assurance standards respectively for different kinds of product, respectively for off-the-shelf one and specialized one.

(3)Establish feedback quick gathering mechanism and formulate a whole quality control system involving departments of quality control, R\&D, manufacture, batch production, new technology, project surveillance and purchase, as well as IT help centre.

(4)Adopt thoughts of Six Sigma and conduct statistical approach, arming at TQM.

(5)Invite third-party supervisory company when 
appropriately, according to project.

Quality management in engineering firms can also be improved by use of procedure design, starting from project design, project plan review, to intermediate inspection and final acceptance (test), following an idea regarding to quality management in college innovation and entrepreneurship project proposed by Wang ${ }^{[[]}$.

\subsection{Improve Departmental Cooperation by Explor- ing Inter-relationships}

Without employee working harmoniously and even conscious of the project common goal, when each department focuses on its own interests, or with direction of no powerful project manager, managerial adjustment on relationships between departments in engineering companies is needed.

For the three usual issues discussed at 2.1.4, five steps are recommended below.

(1) According to 'bunker mentalities, ${ }^{\text {[1] }}$, the project objective and the goal of each phase should be open to every department. Also their outcomes' features and specifications should be shared with each other for the better project performance and final product quality.

(2) By adopting 'value-chain approach', the project manager or the operations manager should break the 'functional boundaries' ${ }^{[1]}$, and take control of every step of the internal value-chain, from purchase to delivery. Other non-value adding functions like HR should also be considered as a whole by the management. The controlling methods for engineering project contains Gantt chart and WBS etcetera.

(3) Some necessary agreements should be reached between departments, otherwise a third party should be introduced for arbitration ${ }^{[6]}$.

(4) Just like supply chain management, inter-relationships management should also pay attention to information and material flows, with help of IT strategy, so as to connect departments substantially.

(5) According to Wright ${ }^{[1]}$, for unhappy workers, who also disturb the final product quality, many measures can be taken such as: atmosphere for self-motivation, higher recognition and responsibility, and expectations 'for growth and advancement'.

\subsection{Other Recommendations for Operations Im- provement}

Except for the above five well-directed suggestions, modern operations management also involves many other concepts which can be utilized to target the unstable product quality, save the costs and finally achieve better operations management. The below points are just to name a few.

(1) Make better workforce scheduling [7], on one hand, tailor each project team to the approximately minimized scope as regard to the labour costs and some costs relevant to employees' behaviors like theft and waste of time. On the other hand, enhance job satisfaction which is basically affected by 'wages, retirement funds, number of leave days' as well as work place selection, accident prevention, morning tea, team building etcetera.

(2)Logistics planning can be detailed and verified as per different situations, including transportation by air, train, or sea, time and route selection, transport company selection, how many people would go escorting. If subcontract is needed then the scope of the subcontracted part is essential to a successful outcome and effectiveness. In the meantime, according to Florian ${ }^{[7]}$, logistics impacts on both environmental and social perspectives should be fully regarded.

(3) In the approval phase of a new product, definite specifications and conditions of design change should be concluded with client so as to avoid any informal design change in the development phase, which could lead to product cost increase ${ }^{[8]}$ and also a compromised quality.

\subsection{Evaluate the Recommendations}

All the recommendations above need to be assessed during or after implementation. If ideally assessed during the implementation with a small step each time, the PDCA principle can be utilized.

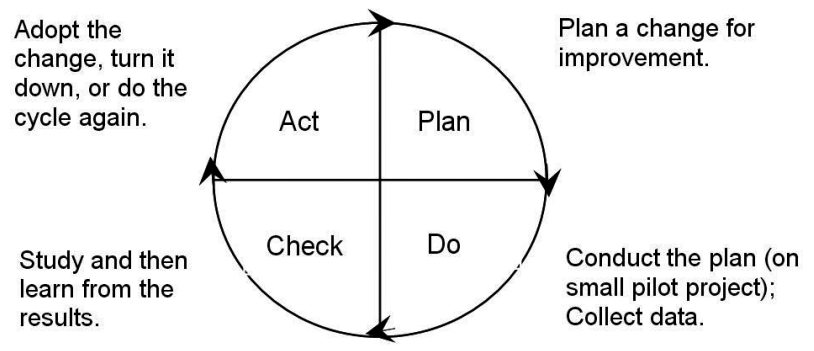

Figure 3. PDCA

At the phase of 'check', checklist can be created both for the immediate change, and the ultimate target of stable high product quality and then greatly de creased costs for after-sales maintenance and repair. 


\section{References}

[1] Wright, J. N. Operations and Supply Chain Service. Victoria Australia: Cengage Learning Australia. 2012.

[2] Zhang Liyuan. A Research on Purchase Application Management of S Science \& Technology Company. Southeast University. 2019. Retrieved from https://kns.cnki. net/KCMS/detail/detail.aspx?dbcode=CMFD\&dbname $=$ CMFD202001\& filename $=1019619853$.

nh\&uid=WEEvREcwSIJHSldRa1FhcEFLUmViU1FGSFYvVnY4R0JZMnQ5LzVxbElmQT0= \$9A4hF_YAuvQ5obgVAqNKPCYcEjKensW4IQMovwHtwkF4VYPoHbKxJw!!\&v=MjQwODg3RGgxVDNxVHJXTTFGckNVUjdxZ111 WnRGeS9nVWJyS1ZGMjZGN1c1RjluSnJKRWJQSVI4ZVgxTHV4WVM=

[3] Brusse, B. COPRAS: Improving the Interface between Research and Standardization. International Journal of IT Standards \& Standardization Research, 2005, 3 (1): 75-81. Retrieved from http://search.proquest.com.ezproxy.aut.ac. nz/abicomplete/docview/203159248/5DB35B35C5DB4AFCPQ/ 9? accountid $=8440$

[4] Yi Tiantian, Tang Shirong. Application and Management on Standardization of library Based on Hardware Modules. Information Technology and Standardization. 2018 (04): 44-46. Retrieved from https://kns.cnki.net/KCMS/detail/detail.asp $x$ ?dbcode $=$ CJFQ \&dbname $=$ CJFDLAST2018\&filename $=$ DZBZ201804025\&v=MDMxNDIEaDFUM3FUcldNMUZyQ1VSN3FmWXVadEZDdmhWTHJPSVRmSmRMRzRIOW5NcTQ5SFlZUjhlWDFMdXhZUzc=

[5] Wang Dajin. Research on the Quality Management and Performance Evaluation of College Innovation and En- trepreneurship Projects. The Theory and Practice of Innovation and Entrepreneurship, 2020, 3(02): 16-20. Retrieved from https://kns.cnki.net/KCMS/detail/detail.aspx?dbcode $=$ CJFQ\&db name $=$ CJFDAUTO\&filename $=$ CXYL202002006\&uid $=$ WEEvREcwSIJHS1-

dRa1FhdXNzY2Z2d3YxN3Y1WjArc245OTZDc2Q1aHprbz0 $=\$ 9 A 4 h F \_Y A u v Q 5 o b g V A q N K P C Y c E j K e n s W 4 I Q-$ MovwHtwkF4VYPoHbKxJw!!\&v=MTYzMTdyek9KalhTWXJHNEhOSE1yWT1GWW9SOGVYMUx1eFITN0RoMVQzcVRyV00xRnJDVVI3cWZZdVp1Rnk3Z1c=

[6] Wu Yiran. Departmental Cooperation Research in the Construction of Quanzhou Urbane Safety Information System Project. Huaqiao University. 2019. Retrieved from https: //kns.cnki.net/KCMS/detail/detail.aspx?dbcode=CMFD\& dbname $=$ CMFD202001\&filename $=1019626620$. nh\&uid $=$ WEEvREcwSIJHSldRa1FhdXNzY2Z2d3YxN3ZDM3VoV 1FqSzRiUFJQcnJVWT0=\$9A4hF_YAuvQ5obgVAqNKPCYcEjKensW4IQMovwHtwkF4VYPoHbKxJw!!\&v=MTk 4MTZQSVI4ZVgxTHV4WVM3RGgxVDNxVHJXTTFG ckNVUjdxZ111WnVGQ25tVUx6S1ZGMjZGN1c2R05mT3 I1RWI=

[7] Florian J. Sustainable Operations. European Journal of Operational Research, 2016, 253(2): 243 - 264. DOI:10.1016/ j.ejor.2016.02.046

[8] Ma Meihong, Zheng Wenjie. Discussion on Costs Management of New Product R\&D. New Technology \& New Products of China. 2018(17): 130-131. DOI: 10.13612/j.cnki.cntp.2018.17.080 